\title{
Quality of institutional care and the elderly: policy issues and options
}

\author{
PATRICIA DAY, RUDOLF KLEIN
}

The debate about standards of care provided in private nursing homes and rest homes has so far been conspicuously short of systematic evidence and specific proposals. Is the quality of care in the private sector inadequate and, if so, in what respects? Does the system of public regulation need to be tightened up and, if so, what changes are needed? These are the questions prompted by public concern. But before addressing them it is important to emphasise that the way in which they are usually presented risks falling into a trap. This is to assume that there is necessarily something special about the private sector of institutional care for the elderly: some form of original sin exclusive to the provision of care for profit. We shall argue that, on the contrary, most of the problems of regulation can be understood only if they are seen as stemming from the nature of institutional care for the elderly, whether publicly or privately provided. If there is concern about standards (as there should be) then it should be an across the board concern. If there is a case for discussing ways of improving the existing machinery for safeguarding standards (as there is) then again the policy options should be examined in the context of the public and private sectors of institutional care taken as a whole.

Taking the latest available figures, for 1984, there were about 280000 places for the elderly in England in a variety of institutions. $^{12}$ Of these, approximately $53000(19 \%)$ were in National Health Service geriatric hospitals and $28000(10 \%)$ in nursing homes; 110000 places $(39 \%)$ were in local authority residential homes and about $90000(32 \%)$ in private and voluntary rest homes. So in 1984 private provision, which we define to include voluntary homes, accounted for over two fifths of all institutional places for the elderly. Indeed throughout the 1980s private nursing and rest homes have been increasing their share of total institutional provision. While the number of geriatric beds has been falling slightly and local authority provision has barely increased the number of private nursing home beds went up by $35 \cdot 6 \%$ between 1982 and 1984 . The number of private residential home beds rose by $42.2 \%$ over the same period. The growth of the private sector in part reflected changes in the supplementary benefits system, although it had started well before the introduction of new rules in 1983 and has since slowed down. As a result of the change in the supplementary benefits rules social security payments now support about two fifths of all the residents in the private sector. ${ }^{3}$ In total, supplementary benefits payments to people in private sector homes rose from $£ 105$ million in 1983 to an estimated $£ 500$ million in 1986 .

In this article we explore the wider concerns in the particular case of nursing homes, which account for roughly a quarter of institutional places. In doing so we draw on interviews and documentary material generated by a research project that is examining the way in which health authorities carry out their statutory responsibilities for registering and inspecting nursing homes. ${ }^{4}$ We do not attempt to look at the regulation of private residential homes by local authorities although this has given more cause for anxiety, some of which has rubbed off on to nursing homes. Although each of the sectors of institutional care-public

Centre for the Analysis of Social Policy, School of Humanities and Social Sciences, University of Bath, Claverton Down, Bath BA2 7AY

PATRICIA DAY, BSC, senior research officer

RUDOLF KLEIN, MA, professor of social policy

Correspondence to: Ms Day. and private, nursing and residential-undoubtedly has its own special characteristics and problems, our main interest here is with issues common to all of them.

\section{What do we know about standards?}

The growing size of the private sector, combined with the increasing injection of public funds through the social security system, has ensured it a high degree of visibility and extensive exposure in the media. Not only is there concern about the standards provided for the elderly; equally, there is disquiet about whether public money is buying adequate quality. Criticisms have come from geriatricians, ${ }^{5}$ trade unionists representing NHS workers, ${ }^{6}$ and members of parliament. ${ }^{7}$ Most recently the Health Advisory Service, responsible for monitoring nationally all services for the elderly, has called for a review of the way in which the legislation governing the public regulation of the private sector is being implemented. ${ }^{8}$

There is a paradox in all this. Anxiety about the private sector has risen at a time when the available, albeit incomplete, evidence suggests that as the number of homes has increased so standards have risen. There are no agreed measures of standards or of quality of care, let alone any statistical data over time; the statistical returns collected by the Department of Health and Social Security every year about staffing levels in nursing homes are meaningless as indicators of standards in the absence of information about the patients being cared for. ${ }^{9}$ Indeed this lack of information, based on agreed and explicit criteria of what is desirable and how it should be measured, is at the root of the problems of regulation that we shall be exploring. Interviews with health authority staff responsible for registering and inspecting nursing homes, however, yield unanimous agreement that standards have been improving. Health authorities have been rewriting their guidelines, which set out their requirements and expectations of nursing homes, in line with the national prototype produced by the National Association of Health Authorities. ${ }^{10}$ In doing so they have generally moved towards more demanding standards both for the physical environment and for staffing levels. Many of the examples of inadequate standards are found in nursing homes that were first registered in less aware and laxer times. Interestingly, the first of the few nursing home cases considered by the Registered Homes Tribunal-the body set up under 1984 legislation to hear appeals against the decisions registering authorities-concerned one such long established home."

This is not to imply that there is no cause at all for disquiet about standards in private nursing homes. Individual clinicians concerned with this sector can cite many examples of poor quality care. ${ }^{12}$ Equally, the concern of registering health authorities is reflected in the frequency of repeat visits paid by inspecting staff to a minority of inadequate homes, generally reported to be about $10 \%$ of the total. ${ }^{3}$ But does this evidence tell us anything about the relative adequacy or otherwise of standards in the private sector of health care? Or does it simply tell us that there are problems in the institutional section of care? What we do know, from a long succession of reports and inquiries, is that these problems can also be found in the public sector. Not only is there a long and dismal history of scandals in long stay institutions for the elderly and others ${ }^{12}$ but despite sustained attempts to improve standards over two decades success remains elusive.

The most recent annual report of the Health Advisory Service . 
points out that "most hospitals in England and Wales still adopt practices which deny privacy, self-determination, choice, rehabilitation, psychological support and homely environments to the old people who spend months and years in their wards," and that some provide treatment of "devastatingly low quality" (our emphasis). ${ }^{8}$ Equally outspoken are the Health Advisory Service's comments on a hospital in a London health authority: "Standards of nursing care in some wards are satisfactory but rarely are they better than satisfactory. In others they are deplorable. ... The attitudes of some nurses to patients is reprehensible and their slovenly approach to care tasks is all too evident."13 And the Department of Health and Social Security's other eye, the Social Services Inspectorate, was only a touch more restrained in its verdict on residential care for the elderly in a London borough: "Life for the residents of the elderly people's homes was satisfactory, even interesting, for those who were mobile, articulate and independent. For disabled, frail or confused residents, however, the homes were failing to provide basic care and support to a satisfactory standard." 14

The evidence, therefore, is that problems of maintaining standards are common to all forms of institutional care for the elderly, whether public or private, whether provided by the NHS or by local authorities. And, so far as the relative distribution or prevalence of problems in the different sectors is concerned, the evidence needed to come to any conclusion is quite simply lacking. All we can be certain about is that conditions reflect the sheer difficulty of providing a decent environment for old people who are in institutions largely if not wholly because society, in the shape of their relatives, friends, and neighbours, is no longer willing or able to cope with them in their normal settings. Looking after frail, confused, and incontinent old people is extraordinarily demanding, both physically and emotionally', and may at times become unbearably so. Moreover, it is a function which often tends to be left for much of the day and most of the night to the least trained, least skilled, and least well paid members of staff: aides, auxiliaries, and domestics. ${ }^{15}$ The only sure way of avoiding scandals in institutions is to close them down, hardly a feasible policy option given the continuing increase in the number of over $85 \mathrm{~s}$ and the failure of the community care strategies so far adopted. ${ }^{16}$ And the most promising way of analysing ways of promoting standards is by concentrating on factors common to all forms of institutional care rather than assuming that the private sector's failings can be exclusively traced to its own, particular brand of delinquency. It is with this consideration in mind that we now turn to the specific issues raised by the public regulation of standards in the private sector of health care provision for the elderly.

\section{Defining and enforcing standards}

When scandal breaks into the newspaper or television headlines, whether in the private or the public sector, the facts tend to speak for themselves. The evidence of callous or incompetent treatment of the elderly is usually so gross that there is no need for argument about how to define standards or quality. If people are left lying in soiled beds, if they have no clothes of their own, if they fear physical abuse we know that things have gone badly wrong. But scandal is a poor regulator. The real challenge lies in defining benchmarks which allow us to know as a matter of routine, and in good time, that care is being provided to acceptable standards and to assess changes over time: to place specific, delinquent institutions into the wider context. Only so, for example, can we tell whether major changes in public policy, whether intended or unintended-such as the incentives to growth provided by the social security system-affect the quality of what is being provided and whether individual scandals indicate cause for general concern or merely represent the inevitable, but exceptional, aberrant case.

In analysing what is being done, and discussing what might be done, the best starting point is Donabedian's typology of approaches to the definition and measurement of quality in medical care ${ }^{17}$ Quality of care, he points out, may be defined and measured in terms of structure, processes, or outcomes. The first means setting standards in terms of inputs: the kind of physical environment and staffing levels deemed necessary to provide good quality care. The second means setting standards in terms of the processes, or good professional and organisational practices, thought necessary to deliver good quality care. The third means setting standards in terms of the desired outcomes for the patients. Traditionally, the emphasis in the definition of standards in nursing homes has been on structure or inputs. Thus the regulations issued by the DHSS in 1984 has a long list of input requirements, specifying that nursing homes' owners must provide "adequate professional, technical, ancillary and other staff," "adequate accommodation and space," "adequate light, heating and ventilation," and so on. ${ }^{18}$ In each case "adequate" is defined, somewhat tautologically, as "sufficient and suitable." It is then left to individual health authorities to spell out what adequacy means in the guidelines they produce for home owners, usually drawing on the model from the National Association of Health Authorities.

The guidelines lay down, for example, the minimum size of the rooms for patients (normally 107 square feet for a single room) and for public space, as well as the design and siting of the kitchen, laundry, and other facilities. They are strong on fire precautions. And while most guidelines do not specify precise staff to patient ratios, since these will in part depend on the physical layout of the building and the characteristics of the patients, health authorities will generally lay down detailed staffing requirements before licensing a home. The guidelines also prescribe some standards in terms of processes. For example, in the case of record keeping and the control of drugs, the standards follow specific statutory requirements. Individual health authorities may also have their own housekeeping standards; thus several give precise details about the kind of meals patients should have. Most important of all, although also most problematically, guidelines emphasise-in line with legislation, DHSS circulars, and the National Association of Health Authorities - that the priority objective of nursing homes is to provide high quality care to patients. To quote the guidelines of one health authority with a large number of nursing homes and a sophisticated approach to regulation, "Patients should live in comfortable, clean and safe surroundings and be treated with respect and sensitivity to their individual needs and abilities. All patients should be encouraged to enjoy as normal and as full a life as possible, and this should include the opportunity to make decisions regarding their lifestyle. There should be a planned programme of care for each person, which has been agreed with the patient and the medical practitioner."19

\section{Structural and process standards}

The importance of structural and process standards tends to vary at different stages of the regulatory cycle. The structural standards are, clearly, crucial when nursing homes are registered: they represent, as it were, the conditions deemed to be necessary to create the environment in which the delivery of decent quality care is possible. They are obviously not a sufficient condition, since it will be the professional and organisational processes which will determine whether such care is actually delivered. The process standards are therefore crucial at the inspection stage in the regulatory cycle: health authorities have a statutory duty to inspect at least twice a year. It is at this point that inspection staff have to determine whether or not care of adequate quality is being delivered, whether or not processes are being carried out according to appropriate professional standards, whether or not the staff of the nursing home are indeed treating patients with respect and sensitivity to their individual needs.

It is a system that makes great demands on the regulatory staff. Firstly, standards in nursing homes (as in other institutions) may change rapidly. If the nurse in charge is replaced by a less competent one standards may crumble overnight. And staff changes are not necessarily synchronised with the biannual visits. Secondly, most standards of good "process" in nursing homes have not been codified, and it may well be that the more subtle, elusive dimensions of quality will always resist codification. Indeed the act of codification may in some instances simply produce rigidities and substitute rules for good manners. Inspection must depend, therefore, on the exercise of professional judgments by the inspection teams in their face to face contact with the staff and patients of nursing homes. Thirdly, while the legislation requires inspection staff to make sure that standards in the private sector are broadly comparable with those in the NHS there is no definition of the latter; and these vary enormously, anyway. For example, many health authorities are seeking to stop the use of restraints in nursing homes in line with Health Advisory Service policy. Yet the Health Advisory Service itself reports the "widespread, thoughtless use of restraints" in NHS institutions. ${ }^{8}$ So which standards are the regulators supposed to enforce-the ideal or the actual? And if they try to enforce ideal NHS standards will they be squashed by the Registered Homes Tribunal?

In summary, the present regulatory system has many advantages. It is flexible and can take account of local conditions. It is informal and rightly puts much emphasis on including home owners as partners in a joint endeavour to maintain or improve professional practices through persuasion and education. But it does depend on the exercise of discretion by 196 different sets of inspectors. Some degree of discretion is not only inevitable but desirable in all forms of regulation, whether of nursing homes or water pollution..$^{20}$ But, as things are, we do not know systematically how districts 
use their discretion and how, in practice, they interpret vague national standards based on ill defined notions of adequacy. Nor, to return to our central theme, is it possible to come to any judgments about movements in standards over time in response to growth in provision, changing government policies, or demographic trends. In the next and concluding section we therefore analyse some of the available options if policy towards institutional care for the elderly is not to remain a form of blind man's buff.

\section{Some options for policy change}

There is every likelihood that both the debate about standards and pressure for changes in the present regulatory system will continue. This is not just because of the weaknesses in the system analysed above. It is also because of the increasing involvement of the government in the financing of private institutional care. A system that allows no accountability for public money spent, no way of checking whether the Treasury is getting value for money or the beneficiaries are getting proper care does not seem likely to survive much longer. A DHSS working party (the second to be set up within two years) is considering the implications of the unplanned, uncontrolled explosion in public expenditure. It is a debate that, as we shall argue in analysing some of the available options, has implications for the regulation both of the private and of the public sectors. For the irony is that by examining the problems in the regulation of the private sector by the public sector it becomes clear that most of the considerations point towards the need for strengthening the system for the regulation of the public sector as well. In terms of setting explicit standards and monitoring them it is clear that the two are logically and practically linked.

The first option for policy change is institutional reform: the nationalisation of regulation. If local diversity is the problem, if there is doubt about whether health authorities are consistent in their judgments about standards and their rigour in enforcing them one solution might be to set up a national licensing agency and inspectorate. ${ }^{21}$ Administratively this could be done. New York State, for example, regulates three times more nursing home beds than there are in the whole of England. But there is a price to be paid for seeking this level of consistency. The experience of New York suggests that the size of the staff needed means that the regulatory agency spends a great deal of its energies regulating itself. Moreover, if the policy aim were to be to try to achieve perfect consistency of standards across all sectors-private and public, nursing and rest homes-the size of the regulatory task would become even more formidable.

An alternative option might be to adapt existing institutions by extending the remits of the DHSS's twin inspectorates-the Health Advisory Service and the Social Services Inspectorate-to cover the private sector. This would mean not only transforming both inspectorates into large regulatory bureaucracies. Equally, it would mean either duplicating one of the main functions of local regulation or destroying one of the main strengths of the present system. Precisely because they are local and informal regulatory authorities can now pay continuous attention to problematic institutions. In contrast, the sporadic visits of the Health Advisory Service and the Social Services Inspectorate teams can provide only a fitful searchlight roaming the national sky, sometimes lighting up abuses or weaknesses, but not casting a steady light on what is happening throughout the country.

\section{Inspecting the inspectors?}

A more modest and realistic variant on this option might therefore be to charge the Health Advisory Service and Social Services Inspectorate with inspecting the inspectors-that is, looking at local regulatory policies and practices as part of their remit. A precedent for this has already been set, since the Social Services Inspectorate has been asked by the DHSS to report on the regulation of residential homes by local authorities. If regulation inescapably means the application of professional judgments it may help local registration and inspection staff to be able to discuss their policies with their fellow professionals in the Health Advisory Service and Social Services Inspectorate teams. At present one of the striking features of regulation is the isolation of the staff concerned and the lack of any systematic discussion across districts about how best to carry out their tasks. ${ }^{22}$ Given that most of the approximately 100 full time equivalent regulatory staff do the job as only one among many others and that only a handful of districts have enough nursing homes to justify a full time regulatory staff the importance of generating dialogue about what is being done would seem to be considerable.

But creating national institutions is only sensible on the assumption that this represents a move towards the setting and enforcement of national standards. If there are no such standards then it would seem somewhat ludicrous to invent machinery for enforcing what does not exist. And if there are such standards do we need a national institution to enforce them? If national institutions like the Health Advisory Service and the Social Services
Inspectorate had succeeded in generating explicit criteria for judging whether or not adequate quality of care is being provided in the public sector we would now have the instruments needed by local regulators to assess what

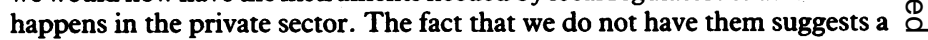
common weakness cutting across the public and private divide and a shared $c$ need to develop instruments for assessing standards in both sectors.

In discussing the present system of nursing home regulation we emphasised $\overline{\bar{J}}$ the importance put on structural or input standards (to return to Donabe- Do dian's typology). And this, too, has been the strategy followed in the public $\mathbb{\Phi}$ sector, where the response by governments to successive scandals over the m past two decades has been to try to improve standards by increasing inputs, particularly staffing. In the public sector, given financial stringency, this approach is beginning to be questioned ${ }^{24}$; in the private sector, too, this $\stackrel{0}{+}$ approach is likely to be resisted given the increasing involvement of the $\overline{0}$ Treasury in its financing. In any case, inputs are only enabling factors: they cannot guarantee successful outcomes for patients.

So why not move towards the measurement of outcomes? If we $\stackrel{\mathbb{Q}}{\Omega}$ could devise standards which can be expressed and measured in terms of the quality of care as reflected in the condition of patients, would we not be in a position to generate a national picture, giving a comparison of the position in all sectors? And could not local $\vec{\omega}$ regulators then be left to carry out their task in the knowledge that $\stackrel{\mathscr{S}}{\circ}$ they were enforcing national standards rather than merely using $\frac{5}{3}$ fallible and perhaps variable professional judgments? This, indeed, was one of the main recommendations of an American committee of 0 inquiry, which recently reported on the regulation of nursing os homes. ${ }^{25}$ The same committee also acknowledged, however, that $\mathrm{G}$ outcome indicators, which can be routinely used to measure the quality of life as well as the quality of care, still need to be developed, although many such have been devised as research instruments. Moreover, there must be some doubt about the fundamental conceptual problems in measuring outcome particularly for the very 77 old and very ill living in institutions. For those among the elderly $\mathbb{D}$ whose desired outcome may be a quick and easy passage to the grave how do we measure its achievement? For those suffering from Alzheimer's disease how do we assess quality of life? For those who $\vec{\imath}$ value their own privacy how do we devise measures which do not $\infty$ confuse quality of life with an intrusive insistence on social activity?

\section{Concentrating on negative outcomes}

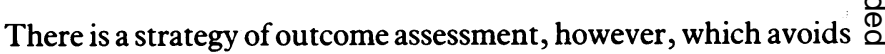
many of these conceptual and practical problems. This is to $\overrightarrow{\vec{O}}$ concentrate on negative outcomes-that is, those outcomes that 3 should be avoidable given adequate quality of care and that, therefore, call for investigation and explanation. This is the approach adopted by New York in developing its sentinel health events system for inspecting nursing homes. ${ }^{26}$ This system calls for the regular assessment of patients to observe whether they are o suffering from conditions like bed sores, whether their behaviour is 3 . being controlled by drugs or restraints, or whether they are poorly groomed, among other indicators. If a nursing home is above average on such indicators this is the signal for a more detailed $\circ$ inspection. Conceptually such an approach, concentrating as it does on what should not happen, is familiar in this country: it was $\sigma$ developed in the maternal deaths inquiry as long ago as $1967 .{ }^{27}$ And $\frac{7}{2}$ there is no reason why it should not be applied in the monitoring of quality of care across all institutional sectors.

But all this, it must be emphasised, cannot be a substitute for N frequent inspection of process. In the case of care for the elderly quality resides largely in process-that is, the way in which patients

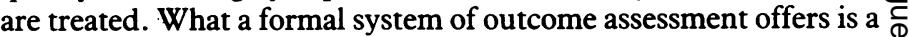
framework within which professional judgment can be exercised $\stackrel{\mathcal{Q}}{\rightarrow}$ and that allows comparisons not only between individual nursing 0 homes but between different sectors of provision, public and $\bar{O}$ private.

Any system of regulation that depends on the regular assessment $\stackrel{\mathbb{Q}}{\mathbb{Q}}$ of patient outcomes is, of course, expensive. But it seems reasonably certain that the government will, in any case, introduce a system of patient assessment at the point of entry into institutional care for $\frac{0}{0}$

Continued on page 387 흘 


\section{Rural Dispensing Committee to survey its work}

Doctors and pharmacists put in $\mathbf{9 5}$ applications to provide pharmaceutical services in rural areas in the year ending 31 March 1986. The job of sifting the applications falls on the Rural Dispensing Committee, which was set up in 1983 to decide how significant changes proposed for dispensing in rural areas could be regulated in the interests of patients.

During the same period, according to the committee's third annual report published last month it received 66 notifications of decisions by family practitioner committees on whether or not a specified area was rural in character and, in its role as the final appellate authority in such cases, the committee dealt with 16 appeals. ${ }^{\prime}$

The committee is now chaired by Sir Alan Marre and has a mixed membership of doctors and pharmacists. The medical members are Dr E C Bramwell, Dr George Cormack, and Dr D J D Farrow.

In his foreword Sir Alan emphasises that the committee has to grant applications to provide pharmaceutical services in rural areas unless to do so would prejudice the proper provision of general medical or pharmaceutical services in those areas. In applying this criterion the committee was, Sir Alan explained, often faced with conflicting views. So far it had been premature to try to establish whether the consequences foreseen had been realised. The committee has decided, however, that it was time to survey the actual results and an initial survey has been launched.

The report contains guidance for family practitioner committees and for representatives of the professions. It draws attention to the requirement to consult all doctors and pharmacists who might be affected by an application and the need for family practitioner committees to avoid delay in undertaking the consultation. Organisation representing the public should also be consulted.

\section{Reference}

1 Rural Dispensing Committee. Third annual report. London: DHSS, 1987.

Workload of Rural Dispensing Committee (RDC), 1 April 1985 to 31 March 1986

\begin{tabular}{|c|c|c|c|c|c|c|c|c|}
\hline & Applications & $\begin{array}{l}\text { Applications } \\
\text { from } \\
1984-5\end{array}$ & Total & $\begin{array}{l}\text { Granted } \\
\text { in } \\
\text { full }\end{array}$ & $\begin{array}{c}\text { Granted } \\
\text { in } \\
\text { part }\end{array}$ & Refused & Outstanding & $\begin{array}{l}\text { Withdrawn } \\
\text { before RDC } \\
\text { consideration }\end{array}$ \\
\hline $\begin{array}{l}\text { Applications from doctors } \\
\text { Applications from pharmacists } \\
\text { Appeal to Secretary of State }\end{array}$ & $\begin{array}{l}56 \\
39\end{array}$ & $\begin{array}{r}27 \\
2\end{array}$ & $\begin{array}{l}83 \\
41 \\
40\end{array}$ & $\begin{array}{c}49 \\
23 \\
3 \text { allowed } \\
10 \text { rejected } \\
15 \text { to be determined }\end{array}$ & $\begin{array}{c}10 \\
2 \text { rejected }\end{array}$ & $\begin{array}{l}11 \\
11 \\
5 \text { rejected } \\
5 \text { to be determined }\end{array}$ & $\begin{array}{l}6 \\
3\end{array}$ & $\begin{array}{l}7 \\
4\end{array}$ \\
\hline
\end{tabular}

\section{Quality of institutional care-continued from $p 386$}

reasons that have nothing to do with any concern about quality and everything to do with a concern about public spending. There have already been discussions between the DHSS and the local authorities about devising a system whereby the latter would assess applicants for social security support in private residential homes. The aim in this is to protect public funds by limiting eligibility to those who would be deemed to "need" residential care if they were applying for a place in a local authority home. Such a screening process would be highly problematic, not least because there is no objective measurement of "need" in this context. ${ }^{28}$ Crucial for our analysis, however, is the fact that if such assessment takes place for residential homes then logically it has to be extended to nursing homes: otherwise frustrated applicants would simply switch to a (more expensive) nursing home. And if assessment is extended to nursing homes health authorities will inevitably be concerned. In turn, the logic of across the board assessment for the private sector would be to standardise assessment for entry to all forms of institutional care, whether private or public. And once the principle of assessment at the point of entry is conceded it will be difficult to resist the argument for regular assessments to check whether there is a continuing requirement for institutional care. Given the likelihood of this kind of development over the next few years for reasons of financial control, it seems all the more important to consider now how such a system of patient assessment can best be used for quality control as well.

But improving the formal techniques of regulation, although necessary in order to discipline individual judgments and diverse local practices, cannot of itself guarantee quality. It can provide a framework. It can generate signals. It can allow us to compare quality in different sectors of provision over time. It cannot, however, provide the kind of sustained professional and social control needed to balance the tensions inherent in institutional care. By giving more visibility to what happens in institutions, by involving more professionals such as general practitioners or more representatives of the community, we may still not be able to guarantee high quality for 24 hours a day. But by removing the shelter of institutional invisibility we greatly increase the chances of stopping the unacceptable and preventing the inadequate from setting in concrete.
The research project on which this article is based is funded by the Nuffield Provincial Hospitals Trust.

\section{References}

1 Larder D, Day P, Klein R. Institutional care for the elderly: the geographical distribution of the publicl private mix in England. Bath social policy paper No 10. Bath: Centre for the Analysis of Social Private mix in 1986.

2 Laing and Buisson. Care of elderly people. London: Laing and Buisson, 1985.

3 Social Services Committee. Fourth report from the Social Services Committee 1985-6: public expenditure on the social services. London: HMSO, 1986. (HC 387)

4 Day P, Klein R. Maintaining standards in the independent sector of health care. Br Med $\mathcal{J}$ 1985;290:1020-2.

5 Godber C. Private rest homes: answers needed. BrMed f 1984;288: 1473-4.

6 Godber C. Private rest homes: answers needed. Br Med f 1984;288:1473-4.

7 National Union of Public Employees. Cashing in on care. London: NUPE, 1985. Lcial Services Committee. Second rep

8 NHS Health Advisory Service. Annual report, 1985-1986. Sutton: Health Advisory Service, 1986.

9 Day P, Larder D. Nursing manpower in private and voluntary nursing homes for the elderly. Bath: Centre for the Analysis of Social Policy, 1986. (Bath social policy paper No 8.)

10 National Association of Health Authorities in England and Wales. Registration and inspection of nursing homes. Birmingham: NAHA, 1985.

11 Registered Homes Act 1984. Registered homes tribunal. London: HMSO, 1986.

12 Martin JP. Hospitals in trouble. Oxford: Blackwell, 1984.

13 NHS Health Advisory Service. Report on services for mentally ill people provided by the West Lambeth health authority. Sutton: Health Advisory Service, 1986.

14 Department of Health and Social Security, Social Services Inspectorate. Inspection of residential care for elderly people and for children in the London borough of Southwark. London: DHSS, 1986. 15 Vladeck BC. Unloving care: the nursing home tragedy. New York: Basic Books, 1980.

15 Vladeck BC. Unloving care: the nursing home tragedy. New York: Basic Books, 1980. London: HMSO, 1986.

17 Donabedian A. Evaluating the quality of medical care. Milbank Memorial Fund Quanterly 1966;44:166-206.

18 The Nursing Homes and Mental Nursing Homes Regulations 1984. London: HMSO, 1984. (SI 1578.) 19 Canterbury and Thanet Health Authority. Nursing home registration and inspection handbook. Ramsgate: Canterbury and Thanet Health Authority, 1985.

20 Hawkins K. Environment and enforcement. Oxford: Clarendon Press, 1984.

21 Higgins J. A consultation on the accreditation of residential care homes, nursing homes and mental mursing homes. London: King's Fund, 1985. (King's Fund project paper No 56.)

22 Bennett J. Private nursing homes: a survey of the current inspecting staff and their training needs in the south east Thames region. Brighton: Brighton Health District, 1986.

23 Department of Health and Social Security. Review of the costs incurred by health authorities in the registration and inspection of private nursing homes and hospitals. London: DHSS, 1985.

24 Day P, Klein R. Central accountability and local decision making: towards a new NHS? Br Med $\mathcal{F}$ 1985;290:1676-8.

$1985 ; 290: 1676-8$.
25 Institute of Medicine. Report of a study by the committee on nursing home regulation. Washington DC: Institute of Medicine. Report of a study

26 Axelrod D, Sweeney RD. Report to the governor and the legislature on the new surveillance process for New York state residential health care facilities. Albany, New York: New York State Department of Health, 1984.

27 Department of Health and Social Security. Report on confidential enquiries into maternal deaths in England and Wales 1967-1969. London: HMSO, 1972.

28 Challis L. Robbing Peter to pay Paul-handsomely. Social Services Insight 1986;1:12-4.

(Accepted 29 December 1986) 